\title{
Coexistence of Complete Metopic Suture and Inca Bone in Thai Skulls: Incidence, Morphology and Clinical Applications
}

\author{
Nutcharin Pakdeewong* and Yoshiyuki Tohno \\ Department of Anatomy, Faculty of Medicine, Chiang Mai University, Chiang Mai 50200, \\ Thailand \\ *Corresponding author. E-mail: nutcharin.o@cmu.ac.th \\ https://doi.org/10.12982/CMUJNS.2019.0004
}

Received: May 15, 2018

Revised: July 26, 2018

Accepted: September 7, 2018

\begin{abstract}
The incidence of the cranial variations has been investigated in human populations worldwide. Some specific variations, such as metopic suture and Inca bone, are of clinical importance since they might be misdiagnosed as skull fractures in patients with traumatic head injury. The purpose of this study is to investigate the incidence and morphology of the metopic suture and Inca bone in Thai skulls. The crania from the skeleton collection of the Department of Anatomy, Faculty of Medicine, Chiang Mai University, were examined. From our observation, $7.3 \%$ presented with metopic suture; the incomplete type was found in $6.0 \%$ and the complete type was found in $1.3 \%$. Different types of the Inca bone were also detected in $2.0 \%$. Among these, 2 skulls happened to coexist with the complete metopic suture and multiple ossicles. The combination of multiple variations in a single braincase is rare. Therefore, the morphometric data and radiography of both skulls were later recorded. The external morphology of such variations mimicked the skull fracture. The cranial radiographs revealed that the metopic suture and additional bones appeared to have sclerotic margins which cannot be found in fractured skull. The physician should take these variations into account to avoid unnecessary management in patients with a history of head trauma. Concerning its uniqueness, it might also be a useful tool as personal identification in forensic medicine by comparing skulls with the antemortem radiographs.
\end{abstract}

Keywords: Metopic suture, Inca bone, Skull, Thai 


\section{INTRODUCTION}

Metopic or frontal suture is a fibrous connection between the two halves of the frontal bone of the cranium. Previous literature stated that this suture is usually obliterated within two years of age (Skrzat et al., 2004). However, its closure may occur as early as three months postpartum (Vu et al., 2001) or delay until early school age (Skrzat et al., 2004). In some cases, the metopic suture persists beyond normal fusion timing and fails to close. This condition is called persistent metopic suture which is classified into two types: complete and incomplete. The incidence of persistent metopic suture reported by previous studies (Ajmani et al., 1983; Baaten et al., 2003; Castilho et al., 2006) varies between 0 and $35 \%$ in different racial groups.

The Inca bone (Os incae) is a separate bone located at the posterior part of the cranium. It can occasionally be found behind the lambda and situated above the highest nuchal line. Several investigators have reported its variation in number, size, shape, symmetry and frequency in different populations (Srivastava, 1977; Pal et al., 1984; Sasexna et al., 1986; Hanihara and Ishida, 2001a). Its incidence has been described as roughly $0-15.0 \%$.

The knowledge of the anatomical variations is essential for medical practitioners. It helps doctors refrain from unnecessary investigation and treatment, and is also used to identify individuals in forensic medicine. The appearance of the metopic suture and Inca bone is of clinical importance since they were clearly seen from the radiographs, and might be misdiagnosed as skull fractures in patients with a history of head trauma (Baaten et al., 2003; Nayak, 2008). In 2007, Bademci et al. demonstrated a 43-year-old woman complaining a headache with previous head trauma. Her radiograph showed a midfrontal vertical line. The definitive diagnosis was later confirmed as the persistent metopic suture by the 3D CT and Multiplanar Reformat scans. They stated that this variation can mimic the skull fracture. Another, the presence of cranium variations could be used as personal identification in forensic medicine. Fujita et al. (2002) reported that the Inca bones were incidentally discovered in two skulls during an autopsy. Individual identification was then taken by comparing the skulls with antemortem cranial radiographic images.

From our literature review, the incidence of metopic suture and Inca bone was not clarified in Thai population living in the north region. Therefore, the purpose of this study is to investigate the incidence and morphology of the metopic suture and Inca bone in northern Thai skulls.

\section{MATERIALS AND METHODS}

Adult human skulls were obtained from the modern skeleton collection at Department of Anatomy, Faculty of Medicine, Chiang Mai University. The protocol was considered to be ethically approved by the Research Ethics Committee of Faculty of Medicine, Chiang Mai University. Crania with incomplete calvaria and gross pathologic condition were excluded from the study. Then, the appearance of metopic suture and Inca bone was carefully inspected by two researchers. Morphometric data of the skulls with combination of the interested variations were recorded by using an outside joint caliper (Sanwa Seiki, Japan). The radiographic imaging was later undertaken by a general X-ray machine (Shimadzu Corporation, Japan). 
The cassette holder was horizontally aligned, on which each skull was placed in the faceup manner. The X-ray beam was set to pass through it in an above-to-below direction. To minimize the unclearness of the image quality, any materials were neither used to support nor fix the skulls during radiography.

The data were analyzed by Chi square test using SPSS 22.0 (SPSS Inc. Chicago, IL). A $P$-value $<0.05$ indicated the statistical significance.

\section{RESULTS}

One hundred and forty nine (107 males and 42 females) skulls with age range between $27-93$ years were examined. Table 1 displays the relationship between the presence of each variation and sexes. Metopic suture was found in both incomplete $(6.0 \%)$ and complete $(1.3 \%)$ types. Different types of the Inca bone were detected in $3(2.0 \%)$ skulls. The results displayed that the incidence of the complete type of metopic suture was lower than the incomplete one.

Table 1. Sex differences in the incidence of interested cranial variations.

\begin{tabular}{lcc}
\hline Variations & Male & Female \\
\hline Metopic suture & 2 & 0 \\
- Complete & 2 & 7 \\
- Incomplete & 3 & 0 \\
Inca bone & 2 & \\
\hline
\end{tabular}

Table 2 shows that the complete metopic suture was present only in male skulls, and female skulls just exhibited the incomplete type. The incidence of the metopic suture was significantly different between males and females $(P=0.002)$. Additionally, the Inca bone was found only in male skulls (Table 3 ). However, from the statistical analysis, the presence of the Inca bone was not sexually dimorphic $(P=0.273)$.

Table 2. Comparison of the incidence of the metopic suture between male and female.

\begin{tabular}{lccc}
\hline \multirow{2}{*}{ Sex } & \multicolumn{3}{c}{ Metopic suture N (\%) } \\
\cline { 2 - 4 } & Complete & Incomplete & Absent \\
\hline Male & $2(1.9)$ & $2(1.9)$ & $103(96.3)$ \\
Female & $0(0.0)$ & $7(16.7)$ & $35(83.3)$ \\
\hline
\end{tabular}

Table 3. Comparison of the incidence of the Inca bone between male and female.

\begin{tabular}{lcc}
\hline \multirow{2}{*}{ Sex } & \multicolumn{2}{c}{ Inca bone N (\%) } \\
\cline { 2 - 3 } & Present & Absent \\
\hline Male & $3(2.8)$ & $104(97.2)$ \\
Female & $0(0.0)$ & $42(100.0)$ \\
\hline
\end{tabular}


Out of the three skulls with Inca bone, 2 skulls happened to coexist with the complete metopic suture and multiple ossicles. The radiographic imaging was later undertaken. The details were as follows:

\section{Skull 1}

The skull belonged to a male who died of asphyxia from drowning at the age of 72 years. The additional midline suture was $10.8 \mathrm{~cm}$ long with a serrated pattern. It ascended continuously from the nasion to the coronal suture, dividing the frontal bone into two halves (Figure 1a).

Caudal to the bifurcation of the sagittal suture was a diamond-shaped Inca bone which was located centrally between the two parietal bones and one occipital bone (Figure 1b). Its left and right horizontal and vertical diagonal lines were measured 6.9 and $6.5 \mathrm{~cm}$, respectively. Its inferior angle was located approximately $1.5 \mathrm{~cm}$ above the external occipital protuberance. According to the classification by Hanihara and Ishida (2001a), the appearance belonged to the type V.

In the vicinity of the lambdoid suture were noted small wormian bones. As shown in Figure 1b, three and four wormian bones were found on the left and right sides of the lambdoid suture, respectively.

The radiographic image of this skull resembled the Water's view. It showed asymmetrical frontal sinuses (Figure 2), whose left side was larger in size than the right one. Both sides were classified as the medium-sized ones according to Guerram et al. (2014). The additional metopic suture appeared to have sclerotic margins.

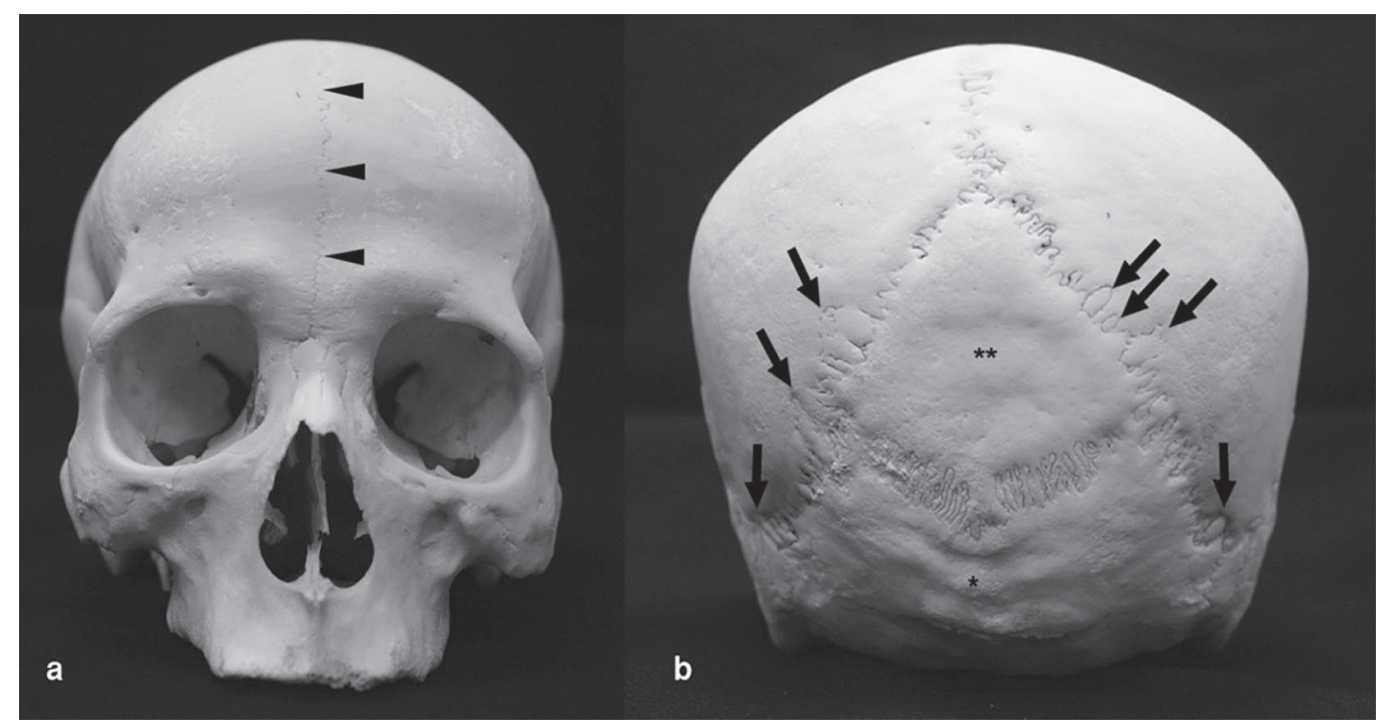

Figure 1. The skull 1. (a) Anterior view; arrowheads indicate the metopic suture. (b) Posterior view; an Inca bone is located in the middle below the lambda. An asterisk (*) indicates the external occipital protuberance. Two asterisks $(* *)$ indicate the Inca bone. Arrows specify some wormian bones. 


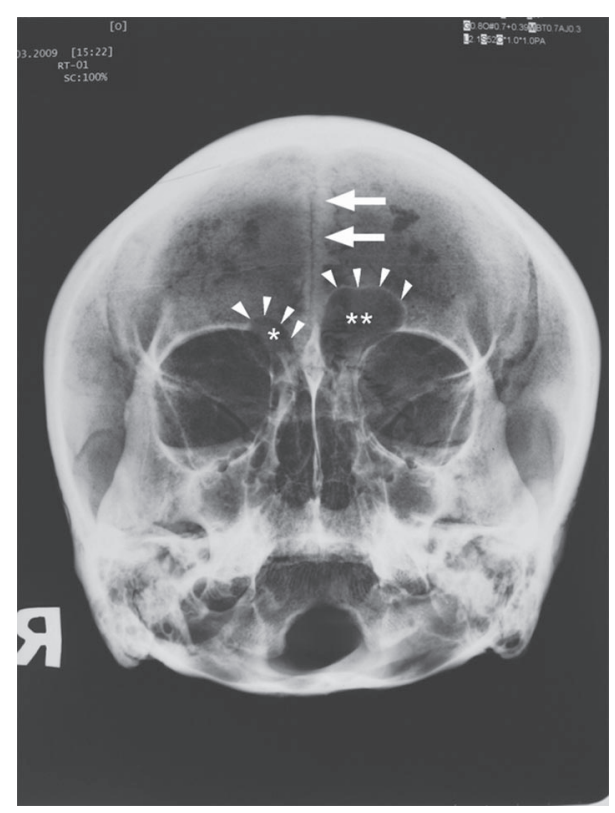

Figure 2. The radiograph shows asymmetrical frontal sinuses in the skull 1. An asterisk (*) and two asterisks (**) indicate the right and left frontal sinuses, respectively. Arrowheads specify the margin of the sinuses. Arrows indicate the sclerotic appearance of the metopic suture.

\section{Skull 2}

The cranium belonged to a male who deceased at unknown age. The additional suture was $11.4 \mathrm{~cm}$ long and ran vertically from the nasion to the coronal suture (Figure $3 \mathrm{a}$ ).

A triangular-shaped Inca bone was found below the left side of the lambdoid suture and above the highest nuchal line (Figure $3 \mathrm{~b}$ ). Its maximum length and breadth were 4.6 and $2.9 \mathrm{~cm}$, respectively. According to the classification by Hanihara and Ishida (2001a), it was classified as the type I.

One ossicle was found at the lambda, and small wormian bones were also found in the territory of the lambdoid suture (Figure $3 b$ ). On the left and right sides of the lambdoid suture, one and two small bones were demonstrated, respectively. The external occipital protuberance was very prominent.

The radiograph of this skull appeared similar to the postero-anterior (PA) view image which revealed bilaterally medium-sized frontal sinuses according to the classification by Guerram et al. (2014) (Figure 4). The metopic suture also had sclerotic margins as seen in the radiograph of skull 1 . 


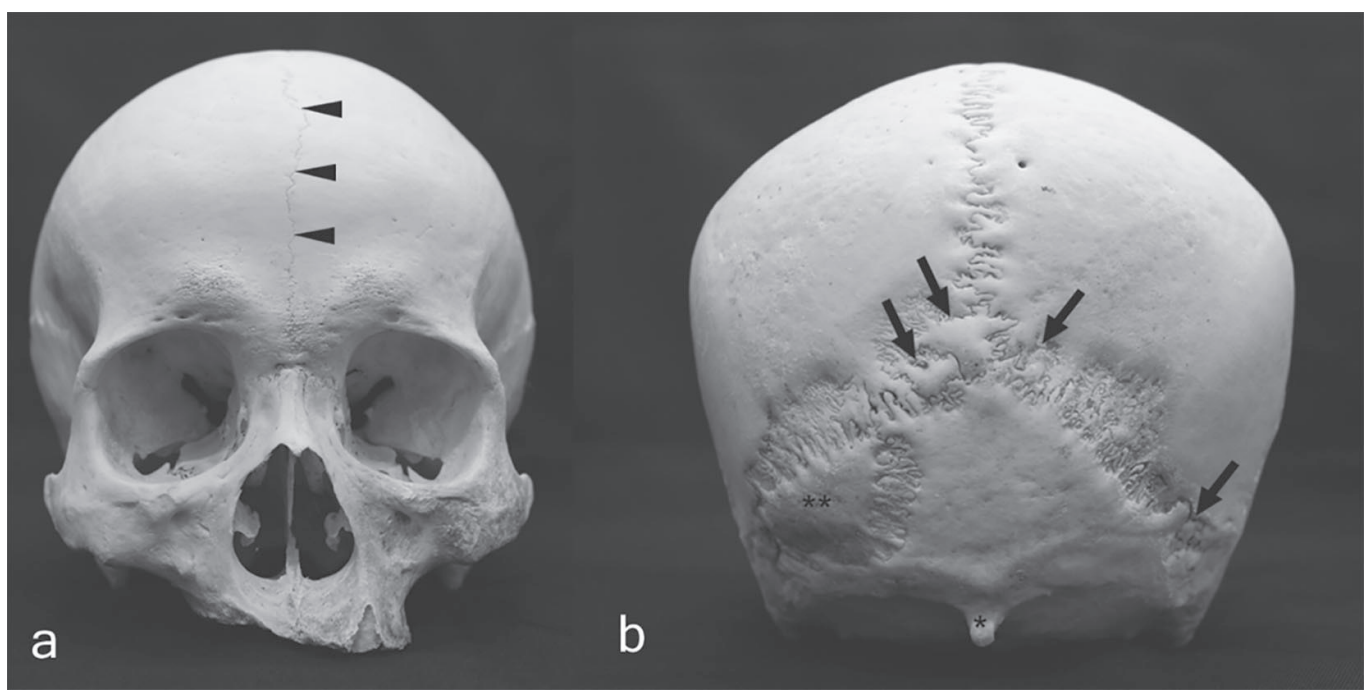

Figure 3. The skull 2. (a) Anterior view; arrowheads indicate the metopic suture. (b) Posterior view; an asterisk $(*)$ indicates the prominent external occipital protuberance. Two asterisks $(* *)$ indicate the Inca bone. Arrows specify wormian bones.

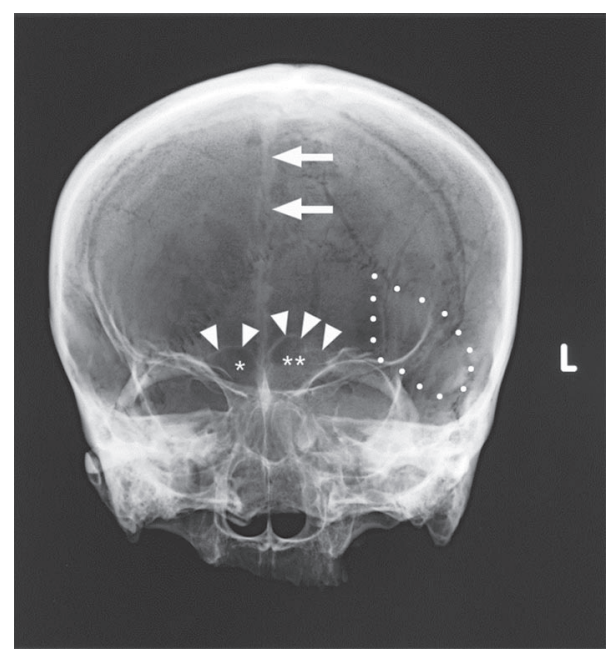

Figure 4. The radiograph shows bilateral frontal sinuses in the skull of Case 2. An asterisk (*) and two asterisks (**) indicate the right and left frontal sinuses, respectively. Arrowheads specify the margin of the sinuses. Arrows indicate the sclerotic appearance of the metopic suture. Dotted line delineates the borders of the Inca bone. 


\section{DISCUSSION}

The incidence of the persistent metopic suture, reported by previous studies, was found to be $1.8 \%$ in Lebanese, 3.3\% in British, 7.5\% in Northeastern Thai, $7.0-9.7 \%$ in Brazilian, $2.0-85.0 \%$ in Indian subpopulations, $11.5 \%$ in Nepalese, $35.0 \%$ in Nigerians, and $3.3-$ $75.0 \%$ in Anatolian. The incomplete type is more commonly found than the complete type (Berry, 1975; Ajmani et al., 1983; Baaten et al., 2003; Bilodi et al., 2003; Castilho et al., 2006; Eroğlu, 2008; Hussain Saheb et al., 2010; Manalgiri et al., 2010; Yadav et al., 2010; Chandrasekaran and Shastri., 2011; Murlimanju et al., 2011; Chakravarthi and Venumadhav, 2012; da Silva et al., 2013; Nallathamby et al., 2013; Masih et al., 2013; Pilli and Sunder, 2013; Aksu et al., 2014; Khandare et al., 2014; Kumar and Rajasekar, 2014; Saikia 2014; Santhosh et al., 2014; Wadekar et al., 2014; Arumugam and Arrchana, 2015; Basha and Sugavasi, 2015; Khamanarong et al., 2015; Kumar and Rajshekar, 2015; Hemalatha and Rao, 2016; Nayakanati et al., 2016; Kundu et al., 2017. Shrestha et al., 2017; Singh et al., 2017). In the present study, nine crania (6.0\%) displayed an incomplete metopic suture, while two crania $(1.3 \%)$ were found to display a complete metopic suture. Accordingly, it could be assumed that the complete type of metopic suture occurred less common than incomplete one. Berry (1975) and Eroğlu (2008) reported that the incidence of persistent metopic suture occurred without sex preference. Contrarily, our results showed that there was a significant sexual dimorphism of the incidence of metopic suture $(P=0.002)$. This dissimilarity could be resulted from the less number of female skulls.

Nakatani et al. (1998) reported that there was no other anomalous finding in the skull with the complete metopic suture. Baaten et al. (2003) studied Lebanese skulls and discovered that a complete type of metopic suture coexisted with the absence of the frontal sinus in seven out of eight subjects.

Torgersen (1951) stated that the existence of metopic suture was influenced by genetics, whereas some other studies suggested that the process of sutural closure was related to many more possible factors, including genetic, hormonal, vascular and mechanical factors with a great degree of variability (Moss, 1958; Madeline and Elster, 1995; Magherini et al., 2015).

The incidence of the Inca bone has been described by several researchers as roughly 1.0 - 4.0\% in Indian subpopulations, $2.0 \%$ in West Anatolian, and 2.5\% in Nigerians (Srivastava, 1977; Pal et al., 1984; Sasexna et al., 1986; Cirpan et al., 2014). Hanihara and Ishida (2001a), who studied in large geographical samples, reported that the frequency distribution of the Inca bone varies between 0 and $12.7 \%$. The incidence of the Inca bone found in this study was $2.0 \%$ being within the reported range.

The occipital squama consists of a supraoccipital bone and an interparietal bone. Embryologically, it has a combined origin from both membrane and cartilage. While the interparietal portion forms in membrane, the supraoccipital portion forms in cartilage (Franken, 1969; Madeline and Elster, 1995). Occasionally, the different embryonic origins give rise to the separation of the membranous occipital squama from the remaining part of the occipital bone, known as the Inca bone.

The Inca bone, in addition, can be easily confused with Wormian bones due to the similarity of their shapes. While the Inca bone is a large geometric-formed bone located in the territory of the occipital squama above the highest nuchal line (Shapiro and Robinson, 1976; 
Hanihara and Ishida, 2001a), Wormian bone is a small, irregular-shaped bone arising from an additional ossification center within the cranial sutures (Hanihara and Ishida, 2001b; Nayak, 2008). Its occurrence varies in size and number (Hanihara and Ishida, 2001b; Cirpan et al., 2015; Praba and Venkatramaniah, 2015; Nikolova et al., 2016; Sah et al., 2017). O'Loughlin (2004) previously reported that the presence of wormian bones was noticed in deformed skulls, but the cause of their formation is still undetermined.

Complete metopic suture, additionally, was reported to be associated with prominent external occipital protuberance (Baaten et al., 2003). In the present study, the prominent external occipital protuberance was found to display in one out of two subject skulls.

There were several studies on the correlation between the presence of complete metopic suture and the development of the frontal sinus. Baaten et al. (2003) reported that there was a significant correlation between the presence of complete metopic suture and the development of the frontal sinus. On the other hand, Bilgin et al. (2013) reported that there was no significant correlation between them. Our results were consistent with the findings of Bilgin et al. (2013). Our two cases had bilaterally medium-sized frontal sinuses. Of the cases with complete metopic suture reported by Guerram et al. (2014), 40.5\% had the medium-sized frontal sinuses.

Das et al. (2005) reported a case that the subject skull exhibited an incomplete metopic suture, an Inca bone, asymmetrical frontal sinuses and multiple sutural deformities. The result of this study is similar to that of the present study, except for a complete type of the metopic suture. During our literature review, there has hitherto been no report on the coincidence of a complete metopic suture, bilateral frontal sinuses, an Inca bone and multiple wormian bones in a single cranium. As formerly discussed, the occurrence of the combination of such multiple variations in a skull is rare, which makes these cases unique.

Metopic suture, both complete and incomplete types, is a very interesting clinical case. Radiographic evidence showed that they might mimic skull fractures (Baaten et al., 2003; Nayak, 2008), particularly in patients with a history of head trauma. The essential finding of serrated and sclerotic margins of such a suture and bones can be applied to distinguish them from fractures (Das et al., 2005). A metopic suture in the Chamberlain-Towne projection can simply be identified by proving its extension into the foramen magnum, which indicates its frontal position (Franken, 1969). Aside from its radiological importance, the presence of any anomalies in a cranium could be used as personal identification in forensic medicine. Fujita et al. (2002) and Badkur et al. (2011) reported that the Inca bones were accidentally found in the skulls of individuals during the forensic autopsy. Their identifications were later done by comparing the skulls with antemortem cranial radiographs.

\section{CONCLUSION}

Cranium variation may occur to some extent. The simultaneous occurrence of a complete metopic suture, an Inca bone and multiple wormian bones in a single skull is rare. It can be concluded that the knowledge of the development and anatomical variation from person to person is beneficial to clinicians because of the possibility that such multiple variations could be encountered in clinical practice and lead to misdiagnoses. 


\section{ACKNOWLEDGEMENTS}

The authors are grateful to Assistant Professor Paiwan Sudwan for permission to use the samples. The authors also would like to thank Associate Professor Juntima Euathrongchit, Division of Diagnostic Radiology, for generous assistance with radiographic imaging and giving the diagnostic opinion, and Dr. Salin Mingmalairak for the comments in developing the manuscript.

\section{REFERENCES}

Ajmani, M.L., Mittal, R.K., and Jain, S.P. 1983. Incidence of the metopic suture in adult Nigerian skulls. Journal of Anatomy. 137: 177-183.

Aksu, F., Cirpan, S., Mas, N.G., Karabekir, S., and Magden, A.O. 2014. Anatomic features of metopic suture in adult dry skulls. The Journal of Craniofacial Surgery. 25(3): 10441046. https://doi.org/10.1097/SCS.0000000000000564

Arumugam, K., and Arrchana, S. 2015. Morphometric study of metopism in human adult dry skulls. International Organization of Scientific Research Journal of Dental and Medical Sciences. 14(7): 10-15. https://doi.org/10.9790/0853-14721015

Baaten, P.J.J., Haddad, M., Abi-Nader, K., Abi-Ghosn, A., Al-Kutoubi, A., and Jurjus, A.R. 2003. Incidence of metopism in the Lebanese population. Clinical Anatomy. 16: 148151. https://doi.org/10.1002/ca.10050

Bademci, G., Kendi, T., and Agalar, F. 2007. Persistent metopic suture can mimic the skull fractures in the emergency setting? Neurocirugia. 18: 238-240.

Badkur, D.S., Sharma, V., and Badkur P. 2011. Medicolegal importance of Inca bone in Forensic Identification. Journal of Indian Academy of Forensic Medicine. 33(4): 358360.

Basha, M.P.A., and Sugavasi, R. 2015. Study of metopic suture in south Indian skulls. International Journal of Research in Medical Sciences. 3(9): 2237-2239. https://doi. org/10.16965/ijar.2016.299

Berry, A.C. 1975. Factors affecting the incidence of non-metrical skeletal variants. Journal of Anatomy. 120: 519-535.

Bilgin, S., Kantarci, U.H., Duymus, M., Yildirim, C.H., Ercakmak, B., Orman, G., Gunenc Beser, C., Kaya, M., Gok, M., and Akbasak, A. 2013. Association between frontal sinus development and persistent metopic suture. Folia Morphologica. 72(4): 306-310. https://doi.org/10.5603/FM.2013.0051

Bilodi, A.K., Agrawal, B.K., Mane, S., and Kumar, A.A. 2003. A study of metopic sutures in human skulls. Kathmandu University Medical Journal. 2(6): 96-99.

Castilho, S.M.A., Oda, Y.J., and Santana, G.D.M. 2006. Metopism in adult skulls from Southern Brazil. International Journal of Morphology. 24: 61-66.

Chakravarthi, K.K., and Venumadhav, N. 2012. Morphological study of Metopic suture in adult South Indian skulls. International Journal of Medical and Health Sciences. 1(2): 23-28.

Chandrasekaran, S., and Shastri, D. 2011. A study on metopic suture in adult South Indian skulls. International Journal of Basic Medical Science. 1(7): 379-382. 
Cirpan, S., Aksu, F., and Mas, N. 2014. Inca bone in human skulls of the West Anatolian population. International Journal of Morphology. 32(1): 275-278. https://doi.org/ $10.4067 / \mathrm{S} 0717-95022014000100045$

Cirpan, S., Aksu, F., and Mas, N. 2015. The incidence and topographic distribution of sutures including wormian bones in human skulls. The Journal of Craniofacial Surgery. 26: 1687-1690. https://doi.org/10.1097/SCS.0000000000001933

da Silva, I.N., de Moraes Fernandes, K.J., Ramalho, A.J.C., Bispo, R.F.M., de Sousa Rodrigues, C.F., and Aragão, J.A. 2013. Occurrence of metopism in dry crania of adult Brazilians. International Scholarly Research Notices. Anatomy. 2013: 1-4. https://doi. org/10.5402/2013/158341

Das, S., Suri, R., and Kapur, V. 2005. Anatomical observations on os inca and associated cranial deformities. Folia Morphologica. 64(2): 118-121.

Eroğlu, S. 2008. The frequency of metopism in Anatolian populations dated from the Neolithic to the first quarter of the $20^{\text {th }}$ century. Clinical Anatomy. 21: 471-478. https:// doi.org/10.1002/ca.20663

Franken, E.A. 1969. The midline occipital fissure: diagnosis of fracture versus anatomic variants. Radiology. 93: 1043-1046. https://doi.org/10.1148/93.5.1043

Fujita, M.Q., Taniguchi, M., Zhu, B.L., Quan, L., Ishida, K., Oritani, S., Kano, T., Kamikodai, Y., and Maeda, H. 2002. Inca bone in forensic autopsy: a report of two cases with a review of the literature. Legal Medicine. 4: 197-201. https://doi.org/10.1016/S13446223(02)00029-9

Guerram, A., Minor, J.M.L., Renger, S., and Bierry, G. 2014. Brief communication: the size of the human frontal sinuses in adults presenting complete persistence of the metopic suture. American Journal of Physical Anthropology. 154: 621-627. https://doi. org/10.1002/ajpa.22532

Hanihara, T., and Ishida, H. 2001a. Os incae: variation in frequency in major human population. Journal of Anatomy. 198(2): 137-152. https://doi.org/10.1046/j.14697580.2001.19820137.x

Hanihara, T., and Ishida, H. 2001b. Frequency variations of discrete cranial traits in major human populations. I. Supernumerary ossicle variations. Journal of Anatomy. 198(6): 689-706. https://doi.org/10.1046/j.1469-7580.2001.19860689.x

Hemalatha, G., and Rao, M.S. 2016. Persistent metopic suture in adult skulls of Andhra Pradesh. International Organization of Scientific Research Journal of Dental and Medical Sciences. 15(12): 4-6. https://doi.org/10.9790/0853-1512030406

Hussain Saheb, S., Mavishetter, G.F., Thomas, S.T., and Prasanna, L.C. 2010. Incidence of metopic suture in adult South Indian skulls. Journal of Biomedical Science and Research. 2(4): 223-226.

Khamanarong, K., Tuamsuk, P., Woraputtaporn, W., Malivalaya, N., Sawatpanich, T., Toomsan, Y., and Iamsaard, S. 2015. Incidence of metopism in adult Thai skulls. International Journal of Morphology. 33(1): 51-54.

Khandare, S.V., Shinde, A.B., and Punpale S.B. 2014. Incidence of metopism in Mumbai region of Maharashtra. Indian Journal of Basic and Applied Medical Research. 3(4): 212-217. 
Kumar, T.H.D., and Rajasekar, S.S. 2014. Metopic suture and its variations. Indian Journal of Basic and Applied Medical Research. 3(4): 42-45.

Kumar, U., and Rajshekar, S. 2015. Study of incidence of metopism in human dry skulls of North Karnataka region. Journal of Research in Human Anatomy and Embryology. 1(1): 6-8.

Kundu, B., Ghosh, I., Mukherjee, P., and DE, A. 2017. Incidence of metopism in Eastern India. International Journal of Anatomy and Research. 5(2.1): 3727-30. https://doi. org/10.16965/ijar.2017.158

Madeline, L.A., and Elster, A.D. 1995. Postnatal development of the central skull base: normal variants. Radiology. 196: 757-763. https://doi.org/ 10.1148/radiology.196.3.7644640

Magherini, S., Fiore, M.G., Chiarelli, B., Serrao, A., Paternostro, F., Morucci, G., Branca, J.J.V., Ruggiero, M., and Pacini, S. 2015. Metopic suture and RUNX2, a key transcription factor in osseous morphogenesis with possible important implication for human brain evolution. Italian Journal of Anatomy and Embryology. 120: 5-20.

Manalgiri, A.S., Satpathi, D.K., Razvi, R., and Naik, D.C. 2010. Study of metopism in skulls of central India. Indian Journal of Forensic Medicine Toxicology. 4(1): 74-77.

Masih, W.F., Gupta, S., Saraswat, P.K., and Aggarwal, S.K. 2013. Autopsy study of metopic suture incidence in human skulls in Western Rajasthan. National Journal of Medical Research. 3(1): 63-65.

Moss, M.L. 1958. Fusion of the frontal suture. American Journal of Anatomy. 102: 141-165. https://doi.org/10.1002/aja.1001020107

Murlimanju, B.V., Prabhu, L.V., Pai, M.M., Goveas, A.A., Dhananjaya, K.V.N., and Somesh, M.S. 2011. Median frontal sutures - incidence, morphology and their surgical, radiological importance. Turkish Neurosurgery. 21(4): 489-493. https://doi.org/ 10.5137/1019-5149.JTN.4293-11.0

Nakatani, T., Tanaka, S., and Mizukami, S. 1998. A metopic suture observed in a 91-year-old Japanese male. Kaibogaku Zasshi. 73: 265-267.

Nallathamby, R., Avadhani, R., Sivarama, C.H., Babu, B., and Jacob, M. 2013. Study on metopic sutures in South Indian skulls. International Journal of Bioassays. 2(8): 10871090. https://doi.org/10.21746/ijbio.2013.08.006

Nayakanati, A.R.J., Bannur, B.M., Rao, M.V.R., Srinivasan, K.R., and Hussain Saheb, S. 2016. A study on incidence of metopic suture in adult human dry skulls. International Journal of Anatomy and Research. 4(2): 2235-2237. https://doi.org/10.16965/ijar.2016.185

Nayak, S.B. 2008. Presence of Wormian bone at bregma and paired frontal bone in an Indian skull. Neuroanatomy. 5: 42-43.

Nikolova, S., Toneva, D., Georgiev, I., Yordanov, Y., and Lazarov, N. 2016. Two cases of large bregmatic bone along with a persistent metopic suture from necropoles on the Northern Black Sea coast of Bulgaria. Anthropological Science. 124(2): 145-153. https://doi. org/10.1537/ase.160530

O'Loughlin, V.D. 2004. Effects of different kinds of cranial deformation on the incidence of wormian bones. American Journal of Physical Anthropology. 123: 146-155. https://doi. org/10.1002/ajpa.10304 
Pal, G.P., Tamankar, B.P., Routal, R.V., and Bhagwat, S.S. 1984. The ossification of the membranous part of the squamous occipital bone in man. Journal of Anatomy. 138: 259-266.

Pilli, N., and Sunder, R.R. 2013. Persistent metopic suture in various forms in South Indian adult skulls - a study. International Journal of Scientific and Research Publications. 3(5): 1-7.

Praba, A.M.A., and Venkatramaniah, C. 2015. A study on the occurrence of wormian bones among the male and female skulls of Tamil Nadu, India. International Journal of Anatomy and Research. 3(4): 1700-1703. https://doi.org/10.16965/ijar.2015.320

Sah, S.K., Chaudhary, D., and Pandey, N. 2017. Study of metopism and wormian bones in dry skulls of human cadavers in Nepal. International Journal of Anatomy and Research. 5(1): 3443-3446. https://doi.org/10.16965/ijar.2016.499

Saikia, R. 2014. A study on metopic suture in cadaveric skulls of Assamese people. Journal of Evolution of Medical and Dental Sciences. 3(44): 10910-10914. https://doi. org/10.14260/jemds/2014/3424

Santhosh, C.S., Vishwanathan, K.G., Gupta, A., and Siddesh, R.C. 2014. Metopic suture incidence and morphology in South Indian human adult skulls. International Journal of Medical Toxicology and Forensic Medicine. 4(1): 6-10.

Sasexna, S.K., Chowdhary, D.S., and Jain, S.P. 1986. Interparietal bones in Nigerian skulls. Journal of Anatomy. 144: 235-237.

Shapiro, R., and Robinson, F. 1976. The os incae. American Journal of Roentgenology. 127: 469-471. https://doi.org/10.2214/ajr.127.3.469

Shrestha, S., Basnet, L.M., and Ghosh S.K. 2017. Study of metopic suture in dry human skulls. International Journal of Science and Research. 6(11): 48-50. https://doi.org/10.21275/ ART20177672

Singh, S., Suman, P., and Panigrahi, A.K. 2017 Morphological variation and occurrence of persistent metopic suture in Indian population. National Journal of Basic Medical Sciences. 8(2): 77-82.

Skrzat, J., Walocha, J., and Zawilinski, J. 2004. A note on the morphology of the metopic suture in the human skull. Folia Morphologica. 63: 481-484.

Srivastava, H.C. 1977. Development of ossification centers in the squamous portion of the occipital bone in man. Journal of Anatomy. 124: 643-649.

Torgersen, J. 1951. The developmental genetics and evolutionary meaning of the metopic suture. American Journal of Physical Anthropology. 9: 193-210. https://doi.org/10.1002/ ajpa.1330090206

Vu, H.L., Panchal, J., Parker, E.E., Levine, N.S., and Francel, P. 2001. The timing of physiologic closure of the metopic suture: a review of 159 patients using reconstructed 3D CT scans of the craniofacial region. Journal of Craniofacial Surgery. 12: 527-532.

Wadekar, P.R., Pundge, S.J., Fulpatil, M.P., and Pandit, S.V. 2014. Study of incidence of metopic suture in adult skulls. Indian Journal of Basic and Applied Medical Research. 4(1): 277-283.

Yadav, A., Kumar, V.N., and Srivastava, R.K. 2010. Study of metopic suture in the adult human skulls of North India. Journal of the Anatomical Society of India. 59(2): 232236. https://doi.org/10.1016/S0003-2778(10)80032-2 